\title{
On the Construction of Identity with Regional Lexical Variant "Kopitiam" in Malaysia
}

Dr. Wong Mun Wui ${ }^{1 *}$, Dr. Wang Tzu-Min ${ }^{2} \&$ Dr. Kemo Badiane ${ }^{3}$

${ }^{1}$ Assistant Professor, School of Foreign Languages, Nanfang College of Sun Yat-Sen University, Guangzhou, Guangdong

Province, China, Email: munwui@yahoo.com

${ }^{2}$ Assistant Professor, School of Foreign Languages, Guilin Tourism University, Guilin, Guangxi Province, China,

Email: jth30kimo2000@yahoo.com.jp

${ }^{3}$ Assistant Professor, School of Foreign Languages, Nanfang College of Sun Yat-Sen University,Guangzhou, Guangdong

Province, China, E-mail: didibadiane@gmail.com

Corresponding Author: Dr. Wong Mun Wui, Email: munwui@yahoo.com

ARTICLE INFO

Received: August 09, 2020

Accepted: September 12, 2020

Volume: 3

Issue: 9

DOI: $10.32996 /$ ijllt.2020.3.9.19

\section{KEYWORDS}

Regional lexical variants, Identity, Functional Grammar Discourse Analysis, Context
ABSTRACT

Regional lexical variants often emerge in interlocutors' daily conversations, but they are unconscious about applying these locally lexical variants in the communications. Why do they use these lexical variants? What is the role of the regional lexical variants in the society? What is the significance of their existence? Why are there different lexical variants existed in different environments and context? In the quest of discovering the nature and the function of the regional lexical variants, an investigation and examination were conducted on the discussions within the online community to observe and analyze a high-frequency local lexical variant "Kopitiam" in the daily dynamic conversation among Malaysians. With the application of Functional Grammar Discourse Analysis this research found that in a specific context and environment, regional lexical variants played an essential role in promoting the establishment of identity among social members in certain region. The interaction between members were developed, the sense of groupness and belonging were strengthened gradually, and eventually societal cohesion could be formed. In addition, this investigation also revealed that the relevant lexical variants could possibly be derived by the differentiation of lexical semantics in certain contexts. The findings in this research provide a deeper understanding on how language interacts and participates in the formation of identification in the societal and individual terms in a specific context.

\section{Introduction}

The influence of environment to language had been underestimated and merely considered as one of the external factors causing the variation of language. However, the anthropologist and linguist Sapir (1912) argued that actually environment which includes social forces and physical environment in some extend provides favorable conditions to the production and maintenance of certain lexicons in the society. He denoted that each individual living and using his language in a specific environment would interact and exchange views with the members of the society consciously or subconsciously based on his life experiences and his perception of the world, therefore the influence of the environment was exerted naturally through individuals' language upon the society. The influence of the environment can be found evidently in the vocabulary, phonology and grammar of the language because language does in fact reflect the environment in which it exists. Sapir (1912) cited a few examples of American Indian languages. For example, Indians who live in the mountainous regions often come into contact with various alpine terrains and landscapes in their daily lives, so there would be diverse nouns in their language describing various mountains, hills, forests and wild lives. The required nouns may appear in relatively high frequency in distribution and might be in considerable quantity. On the other hand, for Indians living by the rivers or coastal land, their language would

K C AL-KINDI CENTER R D FOR RESEARCH AND Your DEVELOPMENT Your gateway to world-class research
Published by Al-KindiCenter for Research and Development. Copyright (c) the author(s). This is an open access article under CC BY license (https://creativecommons.org/licenses/by/4.0/) 
comprise many terminologies which describes different types of currents, the flow of the rivers, water plants and fishes, the density and the distribution of the terminology in their language would be different from the Indians living in mountainous areas. Under the influence of environmental factors, humans are likely to produce different vocabularies and related expressions when they need to distinguish various things or matters.

From the Sapirian perspective, we can deduce that as the environment and modern society change, language that existed in a particular place would eventually change. The change on both sides can be considered proportional and co-occurrence. Obviously, the expected outcome was the variation of language in different forms, such as the emergence of regional lexical variants. But there is more than that. The interlocutors that lived in that particular place and practice the required language would develop a certain sentiment towards the place and the language. For instance, the Kadazan-Dusun indigenous people living in the Northern part of Borneo Island in Malaysia, although some of them migrated and settled in a new environment, even though their language displayed certain variations, their identification maintained in a stable condition or varied in an expectable range after the unavoidable contact with other languages. For Kadazan-Dusun people, they still identified themselves as Kadazan-Dusun. The core of their identity remained rather stable, but simultaneously they also reconstruct and redesign their identification with the ever-changing environment and context. Therefore, language played a crucial part in stabilizing or reconstructing their identification and language might assist the construction of their identification in various ways.

Despite the fact that the environment has a certain influence on language, Sapir (1912) also realized that there are internal factors that contribute to the variation of language. De Saussure's Structuralism Theory might be able to display a thorough anatomy on how language changes internally. From the Saussurean perspective of the concept of signifier and signified, in terms of language, the relationship of the signs and signifiers are formed according to the principle of arbitrary. Yet there is an absolute or restrained relationship between the signs and signifiers in terms of the society (de Saussure, translated by Gao Mingkai (2001). Therefore, once the bonding between signs and signifiers has been crystalized, it tends to stabilize gradually. However, due to the frequent social change and development, the lexical semantics and metaphors of the signs will become more complicated, so as the expression. The lexicons need to expand their lexical functions and semantic spectrum to meet the different demands of the society in communication. In order to express more abstract impressions and thoughts, the interlocutors would consequently stretch the lexical semantics and metaphors coverage in the syntax and grammar found in their language. As a result, the bond between signs and signifiers were loosen. The semantics of lexical variants may be extended, and their usage frontier may be broadened in various contexts.

Therefore, the external abovementioned factors, such as physical environment and social force, the internal factors as shown above such as the structure of the lexicon and semantic, both factors had contributed to the expending and the variation of the nature and function of the language. Regional lexical variants, as the expected outcome of language variation, are considered as specific vocabularies or lexicons that are used in a certain region or area. Their main function is to provide efficient communication in terms of expression and economize the costs of interaction among interlocutors in that particular place. Generally, these regional lexical variants only exist in a specific context and society. In another words, they are territorial and deeply rooted in certain context and environment. Thus, the existence of the regional lexical variants depends on the presences of the context and also the practice of interlocutors. They are more likely to disappear if the required society that used them no longer exist or perhaps the absence of the required context that caused their disappearance. The example cited in this article 'Kopitiam' is a lexical variant commonly used by the members of Malaysian society and possibly the people who live nearby the country such as the Singaporeans. However, in other places, such as the Malay community in southern Thailand or the Malay community in Sumatra, Indonesia, even though Malay language is popular, due to the lacking of the required environment, social and cultural context, this lexical variant would definitely unable to survive and exist.

Assuming that the existence of the regional lexical variants co-exists with a specific context or environment, as a whole, the language of a society may as well be the subject of the context or environment. Therefore, the mentality, ideology, identity of an individual might be affected more or less by the required context or environment. In order to verify this hypothesis, 'Kopitiam', a high frequency lexical variant and the relevant lexical derivation were observed in an actual conversation online. It may help us understand how regional lexical variants such as 'Kopitiam' participates in the construction of individual's identity and also what role it plays in the process of the promotion of the sense of groupness in a society. 


\section{Literature Review}

Human history has shown us that human civilization developed when the process of naming things according to its form and the development of conceptual meaning set sail. With the increasing production of dictionaries and the growing demand of education, the study of lexicons and lexical semantics had become more vital and its growth had captured the attention of educators, grammatists, linguists and especially those who involved with literature and linguistics research. According to the theoretical analysis of lexical semantician and lexicologist Dirk Geeraerts (2010), under the dominance of structuralism semantic research from 1930s to the 1960s, Lexico Field Theory was one of the important structuralist approaches to semantics. It was Weisgerber who laid the foundation for the theory and later on Trier further developed and formulated the theory. A lexical field, then, is considered as a set of semantically related lexical items whose meanings are mutually interdependent and that together provide conceptual structure for a certain domain of reality. Its basic concept is to gather semantically related vocabularies (Geeraerts, 2010). For example, in the lexical field of family members, it would include lexicons such as aunt and uncle or brother and sister. These lexicons are semantically related. Therefore, from the study of semantics, the study of lexicology began to attract attention. Nowadays, with the development of corpus linguistics, the scope of lexicology research had become wider and more diverse. The comparative study of various corpora allows researchers to discover about the existence of regional lexical variants.

Malaysian lexical variants were recognized when lexical comparative studies were conducted. It involved in the study of semantics (Li, 2013; Wong, 2014), language variation (Ang, 2009; Huang, 2009; Huang, 2010), education (Hsu, 2006; Wang, 2010), scientific and technological words (Ward, 2009), academic words (Coxhead, 2000, 2011) and so on. These researches stressed the focus on regional lexical variants and also the words with specific use in certain fields. The researchers usually considered these lexical variants as a type of jargon and they tended to analyze their meaning in the text. Besides, lexical variants are often brought up in the study of social language variation (Su \& Wei, 2014). The regional lexical variants are the subjects of the study and become the examples to reveal the process and results of variation. On the other hand, the studies of lexicons comparing with various registers, regional, and country studies (Tian,1994; Tang, 1995, 2005; Tian, 1998, 2002; Zheng, 2006; Shao \& Liu, 2011; Shao, 2011; Diao, 2012) were mainly attached to the research of morphology, syntactic structure and text analysis.

The current researches mentioned above on Malaysian lexical variants are basically limited to etymology or morphology, semantics and comparative analysis. The priorities of these studies are more inclined to lexical categorization, lexical construction and functions under the direction of the theories including language contact, language variation and mosaic culture theories. These studies observed and analyzed the regional lexical variants from a relatively static perspective. The regional lexical variants are depicted without making connection from the text and context, ignoring the dynamic role of these variants in an active dialogue or real conversations.

In order to discover the real nature of regional lexical variants, this study observes regional lexical variants concerning the culture of 'Kopitiam' in an open online discussion and analyzes the discourse formed by the netizens and evaluates the construction of identity of the netizens through applying the lexical variants. Furthermore, the investigation would also explore how regional lexical variants can pave the way for developing the border of groupness and promote the identity recognition in a diverse Malaysian society.

Regional lexical variants, used in a specific society and context, refer to those vocabularies that reflect and express specific objects or unique concepts within the context of a certain society. 'Kopitiam' and the 'Kopitiam' culture are unique because this entire tradition and the habitual language used can only be found in Malaysian coffee shops and practiced by Malaysian communities in their daily lives. If they want to achieve the purpose of communications using the appropriate language, they must apply the required lexical variants such as: teh-O, kopi-O and so on to communicate in the 'Kopitiam' in Malaysia.

From the anthropological perspective of Sapir's (1912) Language and Environment research paper, it shows that the production of lexicons has a close connection with the environment. However, Sapir (1912) remained doubtful that the relationship of language and environment are directly proportional. He concluded in his hypothesis that, primarily, under certain conditions, language and environment are parallel and proportional in the initial stage. Both develop almost at the same pace. But after the development goes further to a certain extent, their development will be in different speed and they tend to go their separate ways; hence the disproportional happen. When language has the written form, i.e., the literal system develops, it evolves rapidly in terms of lexicology, semantics, phonology, sentence patterns, and discourse. Language can no 
longer progress in parallel with the environment. The complexity of the language making it impossible to identify the initial relationship of language and environment (Sapir, 1912). Thus, it is obvious that language does have a certain relationship with the environment, but it is an indirect relationship. This evidence is sufficient to show us that regional lexical variants are still a reminder of the bonding that existed between language, society and environment. They are the products of mutual influence between society and environment. From this, preliminarily, it is possible that individual's identity may be established through language, especially through regional lexical variants, and consequently it leads to the formation of social cohesion or groupness among interlocutors.

\section{Methodology}

The purpose of this article is to determine the possibility of regional lexical variants to develop the identity of individuals and the productivity of these lexical variants to generate more new variants under certain context. With the observation of a lexical variant 'Kopitiam' in a real and dynamic dialogue, it is possible to discover how this lexical variant derives new va riants and unfold the existing connection between language, environment and society.

In order to observe the activity of lexical variants such as 'Kopitiam' in the real and dynamic conversation among individuals, this research starts collecting corpus data online. In the process of collecting data, this study found that social websites such as Reddit (www.reddit.com) can provide various data. It allows users to post their own original ideas online or submit content links on the Internet to organize an online discussion area. Meanwhile, other users can submit their own comments or replies to other users' comments according to the topic or target posts submitted by others. They can respond, give comments and vote for the comments. Comments with high votes will be defaulted and set to the top of the discussion area, and comments with low votes will not be displayed, thus forming an online community. These chats and communication records can be the resources for the research data. Getting connected, logging in online chatting and posting comments are routines for every user because now almost everyone, is more or less a netizen. The users do online chatting in a relatively relaxed and natural state. Their language expression is natural, unconstrained, and close to reality. Therefore, it is feasible and reliable for us to use it as data for text analysis. The data is an online discussion concerning 'how is 'Kopitiam' culture in your state'. It displayed the similarities and differences in applying the regional lexical variants found in the culture of 'Kopitiam' across Malaysia in the online community of the Reddit website. After a thorough evaluation in the content of the discussion, it is considered suitable to be a research material for text analysis.

Traditionally text analysis was designed to conduct qualitative analysis. But there has been neither a concrete theoretical foundation nor systematic approaches for text analysis (Huang, 2002; Hatch, 1992; Schiffrin, 1994). Systematic Functional Grammar Theory proposed by Halliday (1994) would be suitable to be the basis for the text analysis. Halliday (1994) confirmed that the main purpose of systemic functional grammar is to provide a practical theoretical basis for oral or written text analysis. According to the Systematic Functional Grammar theory, text or discourse has three main functions, first, the ideographic function, i.e., the ability to express conceptual matters; secondly, the interpersonal function, i.e., the capabilities of using language to establish interpersonal relationships; thirdly, text or discourse function, i.e. the competence of communicating with the listeners in terms of organization of words and phrases and also discourse units to achieve communicative purposes and expressions (Halliday, 1994). These functions can be an ideal analytic tool to conduct text analysis. In a specific context, when the speaker and the listener communicate, the discourse as a communicative unit will present a variety of vocabularies, sentences, grammars and forms. At this moment, the investigation can be conducted with the following analytical steps: observation, interpretation, description, explanation and evaluation (Huang, 2002).

Since 'Kopitiam' and 'Kopitiam' related lexical variants are our study subjects, it is necessary to find out the importance and the significance of the lexicon. The regional lexicon 'Kopitiam' refers to coffee shops that can be found everywhere in Malaysia. If the locals want to sit down and chat, they would often 'go to Kopitiam' to have coffee or tea. In spite of the lack of historical records to determine the time of the existence of lexicon 'Kopitiam', it is believed that 'Kopitiam' might appear during the period around World War II. During that time, many Malaysian Chinese worked as coolies in the docks and cities. When they were off from work, they used to go to nearby 'Kopitiam' with friends to have coffee or tea and chat. 'Kopitiam' has multiple functions in the local society. It served as a catering entity that provides various hot and cold beverages such as coffee, milk tea, herbal tea, soft drinks, and foods such as noodles and local dishes, it is also a place for local gatherings, social networking and exchanging information. Going to Kopitiam has become a collective habit and it is an essential part of local people's life. Nowadays it becomes a living space for the integration among various ethnic groups in Malaysia. 


\section{Data Analysis}

The data consisted of 49 comments. The netizens were Reddit.com users and they engaged in an online discussion about 'How is 'Kopitiam' culture in your state'. The netizens were giving comments about how to use certain lexical variants to order food and drinks in the 'Kopitiam' around the country. From the analysis of the cross-section of the data, there are several questions that were worthy of attention: 1 . Does the frequency and distribution of regional lexical variants could indicate the formation of identity? How do speakers and listeners internalize the application of regional lexical variants by developing it into a habit of speaking and the sense of belonging in a society? 2. How are regional lexical variants presented in various syntactic patterns or texts? 3. Does the appearance of several regional lexical variants expressing similar conceptual meaning indicate the semantic variation? For example, the words 'Kopitiam' and 'mamak'? Does semantics variation promote the derivation of other distinctive lexical variants? 4. How do regional lexical variants adapt to the environment? How does the environment provide a living space for them? What roles does society play?

Regarding the first question, in order to verify the frequency and distribution of regional lexical variants in the text did contribute to the formation of individual' $s$ identity, more investigation and research are needed, but there is still room for discussion. From our common sense, if a lexicon is frequently used, it means that its functional value is recognized by the society and the lexicon is more effective and practical in delivering meaning. Therefore, it is more important in the required society. Logically the same if it is the case in the regional lexical variant 'Kopitiam', from the collected data, it is obvious that the higher the frequency of 'Kopitiam' in the text, the wider the range that it can cover, i.e., the coverage of various conversation topics. The more vital of 'Kopitiam' in the lives of the local people. As the above deduction is valid and reasonable, it is possible that regional lexical variants like 'Kopitiam' may leave traces in the individual's memory and may impact individual's psychology in various speech activities, and the sense of belonging to a social group is generated accordingly. At this moment, due to the lexical variant's conceptual meaning is controlled by the context and environment, it can directly connect this context and environment with the sense of groupness of the individual. Hence the individual's identity and the sense of belonging to the context and environment were interconnected by the lexical variant. Let's observe a part of the contents of an online discussion:

Netizen A: In KK everyone goes to this one place to eat roti canai....

Netizen B: In Lintas right?

Netizen A: Yeah Salim. We have been going there since 18 years ago or something...

Netizen A applied "everyone" to integrate himself with the collective consciousness. If he wanted to fulfill his desire for roti canai, a local Indian delicacy, he would without doubt go to Salim, a local coffee shop. This is a consensus or habits among the locals. He has blended in and became one of the locals, he agreed with the general recognition of the locals. He used "since" to project his memory space and emphasized his identity that he has already been to the place 18 years ago. "We" in the chat stressed the condition of exclusivity. It immediately separates the speaker from the rest. "We" is different from other people. "We" have been to Salim. No one else has this special experience but "we". The main purpose of netizen A is to point out that anyone who has the same experience as him or his compatriots would completely understand it. Netizen $B$ resonated with netizen $A$, it is obvious that netizens $A$ and $B$ have developed a sense of belonging to this place. Therefore, it is certain that their identity had developed.

The second question tries to uncover the lexical syntactic patterns from the collected data. It may give us a deeper understanding on how the lexical variants appear in rhetorical questions and declarative sentences. In a dialogue or conversation, the presupposition of a rhetorical question is assumed to be constructed on a recognized universal fact. For example, if a speaker said: " $x$ is $y$, isn't it?" From a logical perspective, it is clear that the speaker has determined a fact that $x$ is $y$, and then the speaker uses rhetorical questions "isn't it?" as follows to seek the assurance or agreement from the listener. In addition, another purpose of the speaker using rhetorical questions is to open more conversation topics and welcome the listener to exchange information with him, especially expecting the listener to agree with his opinions or arguments and ultimately to be accepted in a community or in a society. Hence rhetorical questions may be the key or perhaps an attempt by the speaker to be inclusive in a group. Let's take a look at the following netizen C, who applies lexical variants in rhetorical questions to seek approval, welcome the exchange information and search for acceptance:

Netizen C: Doesn't West Malaysian usually use 'ice' instead of' peng/ping'? 
Netizen C applied the above syntactic pattern to attract a lot of responses in the discussion online. This also revealed that different places or regions may have different lexical variants for ordering drinks. Similarly, in Malaysia, there will be specific lexical variants for the usage in specific places or regions. On the other hand, regional lexical variants also appeared in declarative sentences in a considerable number. Declarative sentences let speakers express their opinions in a direct way, because their sentence structure is rather simple, which economizes communication costs and delivers the speakers' intentions effectively. In the dialogue, the speakers give their statements affirmatively and confidently. Some netizens state their comments based on their own experiences and perceptions authoritatively using the lexical variants in declarative sentences:

Netizen D: Kelantanese use 'beng'.

Netizen E: Not really. I'd use teh peng at a Chinese hawker and teh ais at a mamak. Up to the individual, I guess.

Netizen F: Maybe Canto? Some places use 'syut' instead of based on my experience.

Netizens discussed the terms, namely 'ais' (ice in Malay), 'peng/beng' (ice in Mandarin/Chinese) and 'syut' (ice in Cantonese) on the online discussion. They also commented on how to use these lexical variants and where to use them in order to communicate effectively. They expressed their own experiences and the situations in the reality through declarative sentences. Their main purpose is to persuade others and try to dominate in a discussion in order to earn a certain respect or acceptance in a group. If he has the dominance of convincing others, this suggests that he may possess the access of the key information or that he has a better understanding of the situation, which indirectly strengthens his identity in the group. Therefore, lexical variants in rhetorical questions and declarative sentences strengthen the constructions of individual's identity in a society.

Regarding the third question, this research attempted to observe the reaction of lexical variant 'Kopitiam' in terms of expression in the conversation, especially whether the division of lexical variant 'Kopitiam' would indicate a division of semantics, it produced lexicons with similar meaning such as the lexical variant "mamak". 'Mamak' is referred to a category of the local coffee shops in Malaysia. The complete term is 'mamak stall' which means a catering stall set up on the sidewalk of the streets that is managed or owned by a Tamil Muslim or Indian Muslim stall keeper. Nowadays, some 'mamak stall' had upgraded to a coffee shop. Let's observe the following discussion of the netizens:

Netizen A: ...the lady in KL who looked at me like I had grown an extra head when I asked for a "teh C kaw ping", which is my normal drink in Kota Kinabalu...

Netizen E: Not really. I'd use teh peng at a chinese hawker and teh ais at a mamak. Up to the individual, I guess.

From the above online discussion, it is obvious that netizen E had attempted to distinguish between 'Kopitiam' and 'mamak'. The former refers to coffee shops run by local Chinese tauke or owners; and the latter is also known as 'mamak stalls' which are coffee shops owned by local Indian Muslims shopkeepers. The observation showed that these two lexical variants are semantically similar, both indicate coffee shop. They exist in the similar context. However, in order to distinguish the differences between the two, the speakers tried to distinguish them by the most significant feature, namely, the ownership of the stalls. Therefore, the process of division or derivation took place, such as 'coffee shop' can be differentiated into two distinctive lexical variants, 'Kopitiam' and 'mamak'. Basically, the main product of a coffee shop is coffee, so the abovementioned 'Kopitiam' and 'mamak' both contexts consisted of lexical variants such as 'kopi' (coffee in Malay), 'teh' (tea in Malay), 'milo' (drinks in cocoa powder), and so on. Yet they still have their own characteristics. Kopitiam generally does not have 'teh tarik'; mamak provides 'teh tarik'. For the derived lexical variants, see the following Table 1: 


\begin{tabular}{|c|c|c|c|}
\hline Lexical variants derived by 'Kopi' & $\begin{array}{l}\text { Lexical variants derived } \\
\text { by 'Teh' }\end{array}$ & $\begin{array}{l}\text { Lexical variants derived by } \\
\text { 'Nes-' }\end{array}$ & $\begin{array}{l}\text { Others lexical variants } \\
\text { existed in 'Kopitiam' or } \\
\text { 'mamak' }\end{array}$ \\
\hline $\begin{array}{l}\text { Kopi } \\
\text { Kopi-O } \\
\text { Kopi-O-bok } \\
\text { Kopi-O-kosong } \\
\text { Kopi-C } \\
\text { Kopi-C-kosong } \\
\text { Kopi-peng/ais } \\
\text { Kopi-kaw } \\
\text { Koteh (kopi+teh) } \\
\text {...etc }\end{array}$ & $\begin{array}{l}\text { Teh } \\
\text { Teh-O } \\
\text { Teh-C } \\
\text { Teh-C-kosong } \\
\text { Teh Tarik } \\
\text { Teh tarik-kosong } \\
\text { Teh tarik kaw } \\
\text { Teh tarik peng/ais } \\
\text { Teh peng/ais } \\
\text { Lemon teh } \\
\text { Koteh } \\
\text {...etc }\end{array}$ & $\begin{array}{l}\text { Nescafe } \\
\text { Nescafe-peng/ais } \\
\text { Nescafe-kaw } \\
\text { Neslo (Nescafe+Milo) } \\
\text { Neslo-peng/ais } \\
\text { Neslo-kaw } \\
\text { Nestum } \\
\text {...etc }\end{array}$ & $\begin{array}{l}\text { Milo } \\
\text { Milo peng/ais } \\
\text { Neslo } \\
\text { Kit-Chai peng } \\
\text { Horlick } \\
\text { Soya Cincau } \\
\text { Air lemon } \\
\text {...etc }\end{array}$ \\
\hline
\end{tabular}

Table 1: The Derived Lexical Variants in 'Kopitiam' or 'Mamak'

Apparently, even though 'mamak' seemed unlikely to be considered a derivation from 'Kopitiam' or 'kopi', actually the semantics of 'mamak' is related to the semantics of 'Kopitiam'. Both variants have the meaning of coffee shop. So, there is a possible reason to believe that the two variants are derived from the semantics of coffee shops. Hence, it is reasonable to deduce that due to the differentiation of lexical semantics, the derivatives of lexical variants are generated. The consumers and local interlocutors as well as the owner itself, they need more lexicons to distinguish different categories of coffee shops in terms of management, business models and the products of coffee shops. Therefore, more and more semantic differentiation may occur, more and more lexical variants would appear in the context of 'Kopitiam'. The tendency of derivation would occur as shown in Table 1. This study is based on general circumstance and situations in the 'Kopitiam' or 'mamak' in Malaysia.

Besides, there is another interesting finding from the above discussion between netizens $A$ and $E$. From the comparison of the statements between the two speakers, the statement of netizen A revealed that in Kota Kinabalu, the consumers or the interlocutors there considered 'Kopitiam' or 'mamak' as the same. However, it is a different case from the perspective of netizen E. His comments indicated that 'Kopitiam' and 'mamak' are different. This evidence suggested that the derivation of lexical variants is influenced by a specific context or environment and individual experience. The lexical variants appeared to be the outcome of the interaction between humans and the environment and they indirectly involved in the establishment of the speaker's identity.

Regarding the fourth question which focuses on the adaptation or localization of the lexical variants in a specific context and the role of the society, some lexical variants such as: "kopi-O, kopi-O bok, kopi-C, kopi-C kaw peng/ais ..." and so on were found under the investigation. These lexical variants only exist in the 'Kopitiam' or 'mamak' context. When customers enter 'Kopitiam' and 'mamak' and order a drink, they must use these lexical variants to obtain a corresponding products and service as shown in Table 1, otherwise the communication will be suspended. From the online community discussion of the netizens above, it can be observed that as long as you talk about things or places related to 'Kopitiam' or 'mamak', the relevant lexical variants will simultaneously appear in the context or environment. The speaker can effectively convey the information to the listener instantaneously and the listener can give an appropriate response to the speaker. Therefore, the specific environment or context must exist initially because it provides the fundamental basis for the differentiation of specific lexical variants. Local society and consumers create and practice the specific lexical variants in order to meet the needs of communication based on the specific context. The three parties, i.e., context, lexical variants and interlocutors formed an indispensable closely knitted triangular bond. This triangular bondage had generated the construction of individual's identity. 


\section{Conclusion}

The existence and the function of vocabularies, phonology, syntactic patterns, semantics and grammar are under the influence of environment and society. It reflects the close relationship between language and ecological environment in which they exist. In this investigation, we have observed, studied and analyzed the collected data from an online discussion. We also describe and explain the formation and the role of 'Kopitiam' or 'mamak' and its derivatives in the context of Malaysian society and also the process of the establishment of individual identity. If you enter 'Kopitiam' or mamak, you must use the lexical variants related to 'Kopitiam', otherwise the communication will be suspended, and the speaker will not achieve the goal of communication. Therefore, if the local speakers or consumers use the required lexical variants familiarly, this can ensure that they achieve the purpose of communication and they can integrate into society easily and comfortably, become a part of society, and establish a socially acceptable identity (Edwards, 2009). Localization is considered to be a process of adapting to a new environment. The process of identity recognition requires adaptability. The practice of lexical variants certainly promotes the process of identity recognition.

The process of localization requires the participation among individuals in the society. Each individual gradually forms a consciousness under the influence of social norm and education which enhance their acceptance in society through various social interaction. Consequently, a sense of belonging is eventually formed. Simultaneously, they also developed a patriotic emotion for the environment that they live. Therefore, their identity was confirmed by practicing lexical variants in social communication and this identity also strengthens the connection between social members. So, language plays a role in this process, activates individual sense of belonging, eliminates the gap between people, and forms a consensus social organization (Edwards, 2009). Halliday confirmed his opinion in his collection of essays Language in Society:

"If we say that linguistic structure "reflects" social structure, we are really assigning to language a role that is too passive ... Rather we should say that linguistic structure is the realization of social structure, actively symbolizing it in a process of mutual creativity....Because it stands as a metaphor for society, language has the property of not only transmitting the social order but also maintaining and potentially modifying it" (2007).

The social order mentioned above can be considered as a norm, which forms a tension with individual's thought. The identity promoted by language and various contexts, social factors and interactions can be included as a norm. The regional lexical variants of Malaysia such as 'Kopitiam' or 'mamak' were generated in a specific historical time, space and background. They developed a special bonding with the local Malaysian society. Gradually, the practice of these regional lexical variants was promoted to various places and they participated in the establishment of local people's regional identity. Psychologically, these lexical variants have become a kind of social symbol and eventually a 'Kopitiam' culture was adapted in the local society and environment. This is an interpretation of what Halliday refers to as "linguistic structure embodies social structure, and in the process of mutual creation, language structure becomes a symbol of social structure"(2007). Therefore, the social function of these regional lexical variants is the most valuable and essential asset of the formation of Malaysian society.

This research had only discussed the relationship of language, identity and context in a case study among Malaysians. It would be fair and clear if there are more researches conducted in other societies or other contexts to verify the true nature and functions of regional lexical variants in the language. We believe that there are still rooms for further studies and investigations.

\section{References}

[1] Ang L. H. (洪丽芬) (2009). Analysis on Words Borrowing Between Chinese and Malay Language: The Cultural Integration in Malaysia (华 语与马来语的词汇交流一马来西亚文化融合的表现). Southeast Asian Studies (东南亚研究), 1, 84-88. DOI： 10.19561/j.cnki.sas.2009.01.014.

[2] Coxhead, A. J. (2000). A New Academic Word List. TESOL Quarterly, 34(2), 213-238.

[3] Coxhead, A.J. (2011). The Academic Word List 10 Years On: Research and Teaching Implications. TESOL Quarterly, 45(2), 355-362. https://doi.org/10.5054/tq.2011.254528.

[4] De Saussure, F. ([瑞士]费尔迪南·德·索绪尔) (2001). Linguistique Générale (普通语言学教程), publié par Charles Bally et Albert Sechehaye, avec la collaboration de Albert Riedlinger, 5e edition, Payot, Paris, 1949, translated by Gao Ming Kai (高名凯), Beijing: The Commercial Press.

[5] Diao, Y. B. (2012). From the "Chinese Folk's Community" to the "Global Chinese Language Community": Evolution of the Language Differences and Fusion in the Four Places across the Taiwan Strait, Journal of Yunnan Normal University (Humanities and Social Sciences), 2, 1-5. https://en.cnki.com.cn/Article_en/CJFDTotal-YNSF201202003.htm

[6] Edward, J. (2009). Language and Identity. Cambridge University Press, 21-27. https://doi.org/10.1017/СBO9780511809842. 
[7] Geeraerts, D. (2010). Theories of Lexical Semantics. Oxford University Press.

[8] Halliday, M.A.K. (1994). An Introduction to Functional Grammar. London Edward Arnold.

[9] Halliday, M. A. K. (2007). Collected Works of M.A.K. Halliday: Language and Society: Volume 10. Jonathan J. Webster (Ed), Bloomsbury Academic. Book DOI:10.5040/9781474211901.

[10] Hatch, E. (1992). Discourse and Language Education. Cambridge: Cambridge University Press.

[11] Hsu, T. J. (2006). Teaching English Lexically: The University Word List Is A Good Start. The Proceedings of Taiwan TESOL Conference Paper.

[12] Huang, G. W. (2002). Aspects of Functional Discourse Analysis. Foreign Language Learning Theory and Practice, 4, $25-32$.

[13] Huang, M. Y. (黄妙芸) (2010). The Variation of Regional Chinese Lexicons from the Perspective of Internationalization of Chinese Language- Malaysia as a Case Study (从汉语走向国际化看区域华语词汇变异一以马来西亚为例). Overseas Chinese Journal of Bagui (八 桂侨刊), 12(4), 48-52.

[14] Huang, W. H. (黄婉桦) (2009). A Study of the Difference in Malaysia Chinese and Mandarin Lexicons (马来西亚华语和汉语标准语词语 差异研究) [Master's Thesis, Jinan University (暨南大学)]. https://navi.cnki.net/KNavi/PPaperDetail?pcode=CDMD\&logo=GJINU.

[15] Li, S. A. (李思嗳) (2013). On the Phenomenon of Malaysian Chinese Language Integration: Mamak Stall (以“嘛嘛档”一词探讨马来西亚 华语的语言融合现象), Modern Chinese 现代语文 (语言研究版) , 6, 109-110.

[16] Reddit (n.d.). https://www/reddit.com/r/malaysia/comments/56ehgt/how_is_kopitiam_culture_in_your_state?

[17] Sapir, E. (1912). Language and Environment. American Anthropologist, 14(2), new series, $226-242$. https://doi.org/10.1525/aa.1912.14.2.02a00020.

[18] Schiffrin, D. (1994). Approaches to Discourse. Oxford Blackwell.

[19] Shao, J. M. \& Liu, Z.B. (邵敬敏和刘宗保) (2011). The Representativity of Chinese Community Words and Verification Standard (华语社 区词的典型性及其鉴定标准). Linguistic Research (语文研究), 3, 1-7.

[20] Shao, S. P. (邵淑萍) (2011). A Preliminary Study of the Culture of Special Chinese Lexicons in Malaysia (马来西亚华语特色词文化初探). [Master's Thesis, Suzhou University（苏州大学）]. DOI: 10.7666/d.y1990532.

[21] Su, L. Q. \& Wei, L. J. (苏柳青和韦恋娟) (2014). The Characteristics of Chinese Variations in Malaysia (马来西亚华语变异的特点). Journal of Guangxi Vocational and Technical College (广西职业技术学院学报), 3, 73-78.

[22] Tang, Z. X. (汤志祥) (1995). The differences of Chinese Vocabularies in Mainland China, Taiwan, Hong Kong and Singapore (中国大陆、 台湾、香港、新加坡汉语词汇方面若干差异举例). Journal of Jiangsu Normal University (徐州师范学院学报),1. DOI: CNKI:SUN:XZSB.0.1995-01-026.

[23] Tang, Z. X. (汤志祥) (2005). On the Special Regional Words in Different Chinese Community (论华语区域特有词语). Applied Linguistics ( 语言文字应用). 2, 40-48. DOI: 10.16499/j.cnki.1003-5397.2005.02.006.

[24] Tian, H. G. (田惠刚) (1994). On Similarities and Differences between Overseas Chinese and Modern Chinese Languages (海外华语与现 代汉语的异同). Journal of Hubei University (湖北大学学报), 4, 73-39.

[25] Tian, X. L. (田小琳) (1998). On the Standardization of Modern Chinese Lexicons from the Perspective of Community Words (由社区词谈 现代汉语词汇的规范). Language Planning (语文建设),11, 3-5. DOI: 10.16412/j.cnki.1001-8476.1998.11.005.

[26] Tian, X. L. (田小琳) (2002). A Study of Community Words and Lexical Standardization of Chinese (社区词与中文词汇规范之研究). Chinese Teaching in the World (世界汉语教学), 1, 53-59, 115.

[27] Wang, S. T. (王思婷) (2010). A Comparative Study of Themes and Vocabularies in Singapore and Malaysia's Chinese Teaching Materials ( 新马华文教材课文主题和词汇比较). [Master's Thesis, National Singapore University(新加坡国立大学)]. http://thesis.lib.pku.edu.cn/docinfo.action?learnid=10820087.

[28] Ward, J. (2009). EAP Reading and Lexis for Thai Engineering Undergraduates. Journal of English for Academic Purposes, 8, 4, 294 - 301. https://doi.org/10.1016/j.jeap.2009.10.002.

[29] Wong, W. Y. (黄华迎) (2014). Research of Malaysia Chinese Words (马来西亚华语词语研究). [PhD's Thesis, South West University (西 南大学)]. https://navi.cnki.net/KNavi/PPaperDetail?pcode=CDMD\&logo=GXNDX.

[30] Zheng, N. (郑娜) (2006). Discussion on the Special Phrases in Overseas Chinese Community (试论华人地区的特有词语), Journal of Changchun University (长春大学学报), 9, 34-37. 